\title{
FORMAÇÃO DE PROFESSORES DE GEOGRAFIA E O PROGRAMA INSTITUCIONAL DE BOLSAS DE INICIAÇÃO À DOCÊNCIA: REFLEXÕES SOBRE AS EXPERIÊNCIAS COM AS TÉCNICAS DE ENSINO NO ENSINO MÉDIO
}

\author{
Denizart Fortuna ${ }^{\text {ii }}$ \\ Juliana Nascimento ${ }^{\text {iii }}$
}

\begin{abstract}
Resumo: O presente trabalho foi desenvolvido a partir do Subprojeto de Geografia (Niterói) da Universidade Federal Fluminense, vinculado ao Programa Institucional de Bolsa de Iniciação à Docência (Pibid) da Coordenação de Aperfeiçoamento de Pessoal de Nível Superior (CAPES). Adotamos como temática central os desafios que atravessam as práticas curriculares no ensino de geografia e a formação inicial docente. Buscamos trazer reflexões e alguns dos resultados de trabalho em torno das técnicas de ensino, sua importância nas práticas docentes cotidianas, e, sobretudo, as que vêm sendo desenvolvidas no âmbito desse Projeto. Articulamos essas reflexões à relação ensino-aprendizagem e à relação teoria e prática na formação inicial docente. Esse foi o ponto central de nosso trabalho na unidade escolar Colégio Estadual Manuel de Abreu, situado no bairro Icaraí, no município de Niterói (RJ), no decorrer dos anos letivos de 2014 e de 2015. A nossa investigação acerca das técnicas de ensino desenvolvidas nas aulas de geografia do $2^{\circ}$ e $3^{\circ}$ ano e do Ensino Médio desdobra-se nas seguintes indagações: quais os resultados trazidos para a formação inicial docente e quais as representações que os bolsistas licenciandos envolvidos apreendem sobre tais técnicas e o seu "fazer docente"? Este estudo está baseado em alguns pressupostos, dentre eles as considerações acerca da (1) organização de um curso de geografia escolar; (2) a relação entre teoria e prática na formação inicial docente; e, (3) o papel da abordagem filosófica no desenvolvimento dos objetos/conceitos que dêem sentidos à transformação social essencialmente "positiva".
\end{abstract}

Palavras-chave: Formação Inicial Docente; Técnicas de Ensino; Ensino-Aprendizagem; Programa Institucional de Bolsas de Iniciação à Docência; Ensino de Geografia.

\section{GEOGRAPHY TEACHERS TRAINING AND THE INSTITUTIONAL PROGRAM OF SCHOLARSHIP FOR TEACHING INITIATION: REFLECTIONS ABOUT THE EXPERIENCES WITH TEACHING TECHNIQUES IN HIGH SCHOOL}

\begin{abstract}
This work was developed from Subprojeto de Geografia (Niterói), Universidade Federal Fluminense, linked to the Programa Institucional de Bolsas de Iniciação à Docência (Pibid) of Coordenação de Aperfeiçoamento de Pessoal de Nível Superior (CAPES). Our aim is to present the ideas and some of the results of work around teaching techniques and their importance in everyday practice teachers. This presentation focuses on initial teacher training. This was the central point of our work at school Colégio Estadual Manuel de Abreu, located in Niterói (RJ), during the academic years 2014 and 2015. Our research on the developed teaching techniques in geography lessons of the $2^{\text {nd }}$ year of high school unfolds on the following questions: what results brought to initial teacher training and what representations the undergraduate fellows involved seize on such techniques and their "making teaching"? This study is based on certain assumptions, including the considerations of (1) organizing a course
\end{abstract}


of school geography; (2) the relationship between theory and practice; and (3) the role of philosophical approach in the development of objects / concepts that give way to social transformation essentially "positive".

Keywords: Initial Teacher Training; Teaching Techniques; Teaching and Learning Process; Programa Institucional de Bolsas de Iniciação à Docência; Geographical Education.

\section{Introdução}

Sob os auspícios da Coordenação de Aperfeiçoamento de Pessoal de Nível Superior (CAPES), o Programa Institucional de Bolsa de Iniciação à Docência (Pibid) visa desenvolver maior articulação entre os cursos de licenciatura e as redes públicas de ensino. O Programa oferece bolsas de iniciação à docência aos licenciandos, professores supervisores (docentes das unidades escolares) e aos coordenadores dos projetos de ensino (docentes do ensino superior). Compõe também o Pibid nas Instituições de Ensino Superior (IES) a coordenação de gestão e institucional. O Pibid propõe unir as secretarias estaduais e municipais de educação e as universidades públicas a favor das melhorias de ensino nas escolas púbicas em que o Índice de Desenvolvimento da Educação Básica (Ideb) esteja abaixo da média nacional. A nossa inserção neste Programa está vinculada ao Subprojeto de Geografia (Niterói), submetido ao Projeto de Ensino PIBID, produzido pelos coordenadores gerais da Universidade Federal Fluminense (UFF) e submetido a CAPES em 2008-2009. No entanto, o início do nosso trabalho deu-se a partir de 2014.

Adotamos como temática central os desafios que atravessam as práticas curriculares no ensino de geografia e a formação inicial docente. Buscamos trazer reflexões e alguns dos resultados de trabalho em torno das técnicas de ensino, sua importância nas práticas docentes cotidianas, e, sobretudo, as que vêm sendo desenvolvidas no âmbito desse Projeto. Articulamos essas reflexões à relação ensino-aprendizagem e à formação inicial docente.

A princípio, pensamos que a aprendizagem escolar significa uma interdependência entre o professor, aluno(s) e o conhecimento a ser mediado. Dessa maneira, interessa-nos a ação docente, ou seja, a didática empreendida para compreender determinado conteúdo de ensino, as formas ou como o aprendiz compreende e se apropria do conhecimento. Daí, pensarmos na 
definição da didática como a capacidade teórico-metodológica de estabelecer relações entre os conteúdos/conceitos e o cotidiano vivido pelos alunos (MATURANA, 2001).

Dentre os elementos da relação ensino-aprendizagem, destacamos as técnicas de ensino. Essas encerram uma atividade prática ou um conjunto dessas práticas que colocam em execução habilidades especiais que visam à compreensão dos conteúdos escolares. Isso não significa que a nossa concepção sobre tais técnicas sejam naturais ao processo de ensinar; mas, exatamente o contrário e ainda mais: são deliberadas por aquele que ensina, pois, o mesmo as apreende como condições que dão acesso à aprendizagem. Logo, elas são como "artifícios" porque não deixam de se interpor na relação entre o professor e o aluno, submissas à autoridade e à intencionalidade do primeiro; assim como não se deve concordar com a ideia de que o ensino seja algo eminentemente técnico (VEIGA, 2008). Cabe mencionar que as "qualidades" do conteúdo, ou seja, seus pressupostos epistemológicos e a sua representação, associadas às concepções sobre o conhecimento geográfico e as metodologias de ensino, são referências para a escolha e uso de determinada técnica por parte do professor.

Esse é o ponto nevrálgico do trabalho empreendido no Colégio Estadual Manuel de Abreu no decorrer dos anos letivos de 2014 e no ano de 2015. A nossa investigação sobre as técnicas de ensino desenvolvidas nas aulas de geografia do $2^{\circ}$ e ano do Ensino Médio Regular centra-se em duas questões norteadoras: quais as técnicas de ensino utilizadas e como foi o seu desenvolvimento? Quais os resultados trazidos para a formação inicial docente e quais as representações que os bolsistas licenciandos envolvidos neste Subprojeto apreendem sobre tais técnicas e o seu "fazer docente"?

A inserção desses graduandos no espaço escolar, em nosso Subprojeto, ocorre a partir do acompanhamento das atividades da professora supervisora no horário regular das aulas e também em espaços e horários extraclasses, incluindo oficinas. Construímos um projeto de trabalho a partir da observação das demandas da escola e dos anos escolares com os quais trabalhamos, acompanhado de leituras e discussões teóricas, planejamento coletivo e desenvolvimento de atividades, seguida de reflexão sobre as mesmas. Nesses momentos, avaliamos o desenvolvimento da aprendizagem dos conteúdos por parte dos alunos, bem como os seus resultados na construção das práticas docentes dos licenciandos.

Compõem os objetivos gerais deste trabalho as reflexões sobre o próprio espaço viabilizado pelo PIBID, na condição de um Projeto que propõe maior aproximação entre os licenciandos e o cotidiano escolar para melhor formação inicial docente. Entre os seus 
resultados, estão previstos o aumento da qualidade da educação básica nas redes públicas de ensino e a formação continuada dos professores regentes envolvidos nesta parceria.

Para o presente artigo, elencamos como objetivos específicos a discussão sobre ensinoaprendizagem, considerando para isso o uso de diferentes linguagens no ensino de geografia a partir das técnicas de ensino. Trataremos sobre as atividades Produção de Textos I e II, Colagem com Música. Propomos, também, uma reflexão sobre a relação teoria e prática na formação inicial docente considerando para isso as ações desenvolvidas no Pibid e os resultados obtidos (ainda que parciais), tendo por objeto de estudo o desempenho dos nossos bolsistas de iniciação à docência.

\section{A relação teoria e prática na formação inicial docente: algumas problematizações}

Este estudo está baseado em alguns pressupostos, dentre eles as considerações acerca da (1) organização de um curso de geografia escolar; (2) a relação entre teoria e prática na formação inicial docente; e (3) o papel da abordagem filosófica no desenvolvimento dos objetos/conceitos que dêem sentidos na transformação social essencialmente "positiva", a partir da geografia escolar. Concordamos com González (apud CASTELLAR \& VILHENA, 2010) quanto à organização de um curso de geografia escolar que deve levar em consideração: as finalidades educativas gerais do sistema educacional nas quais se inserem os conteúdos geográficos, isto é, seus pressupostos políticos e filosóficos, e o objetivo educacional do segmento ou ano escolar da área de conhecimento no qual se inserem os conteúdos geográficos. Devem ser consideradas, também, as metas educativas da escola em que estamos trabalhando, o que poderá ajudar na escolha dos conteúdos; a escolha da metodologia que seja coerente com a concepção de ensino que se está desenvolvendo em geografia, definindo, assim, a sequência de conteúdo; o interesse de cada atividade didática por meio da explicação dos objetivos (específicos) dessas atividades em relação ao fio condutor da unidade didática.

Compreendemos que as considerações acima devem estar presentes desde o momento da formação dos licenciandos, uma vez que terão de lidar com essas reflexões e práticas no exercício do magistério. Contudo, permanece uma dicotomia entre a teoria e a prática ou, em termos mais específicos, a dicotomia que perpassa a relação entre a formação de professores na universidade e na escola a partir das culturas formativas vigentes na nossa sociedade e na forma de produção e valorização do conhecimento dentro do espaço acadêmico. Como afirma 
Marinalva Barbosa (2014) em seu texto intitulado O Pibid e as Culturas Formativas no Âmbito dos Cursos de Licenciatura, publicado em 2014, há uma desarticulação entre educação superior e a educação básica que, por sua vez, não está desarticulada da polêmica relação entre conhecimentos específicos e conhecimentos pedagógicos. Segundo a própria, ainda prevalece na construção dos projetos políticos pedagógicos dos cursos de licenciatura a visão bacharelesca, centrada na valorização da formação específica e em detrimento da pedagógica. Em outras palavras, prevalece uma espécie de aversão aos fazeres e saberes ligados à docência. Afetada por essas contradições, a formação pedagógica, muitas vezes, também é realizada de forma fragmentada e descolada das reais necessidades formativas e das práticas realizadas na escola (BARBOSA, 2014).

Tal dicotomia ainda persiste apesar do estabelecimento das Diretrizes Curriculares Nacionais para a Formação de Professores da Educação Básica, em nível superior, de graduação plena (Parecer $n^{\circ}$ 9/2001) emitido pelo Conselho Nacional de Educação. Essas promoveram alterações curriculares nos cursos de licenciatura porque compreende os estágios supervisionados e a prática como componente curricular, além da respectiva duração e extensão ao longo desses mesmos cursos. Segundo a Resolução do Conselho Nacional de Educação ${ }^{\circ}$ 02/2002, de 19 de fevereiro de 2002, em sintonia com as Diretrizes Curriculares para o curso de Geografia (Resolução CNE/CES n 14, de 13 de março de 2002), o objetivo foi "melhor preparar" os docentes da Educação Básica. Para tanto, aumentou a carga horária do estágio supervisionado e a previsão de mais 400 horas de atividades práticas como componente curricular distribuída ao longo de todo a formação (NUNES, 2007). No texto referente às Diretrizes Curriculares Nacionais para a Formação de Professores, justifica-se a sua necessidade em função das alterações realizadas quanto à formação docente, “[...] mais de acordo com a realidade e estrutura atual dos cursos de graduação [...]” (NUNES, 2007, p. 61):

[...] O processo de elaboração das propostas de diretrizes curriculares para a graduação, conduzido pela SESu, consolidou a direção da formação para três categorias de carreiras: Bacharelado Acadêmico; Bacharelado Profissionalizante e Licenciatura. Dessa forma, a Licenciatura ganhou como determina a nova legislação, terminalidade e integralidade própria em relação ao Bacharelado, constituindo-se em um projeto específico. Isso exige a definição de currículos próprios da Licenciatura que não se confundam com o Bacharelado ou com a antiga formação de professores [...]" (Diretrizes Curriculares Nacionais para a Formação de Professores da Educação Básica, 2002, p. 06). 
A professora Ângela Massumi Katuta em seu trabalho intitulado Universidade em ruínas?, publicado na Geografia: Revista do Departamento de Geociências, em 2002, sustenta que haveria a possibilidade de isolar a docência da pesquisa já que a concepção "aplicacionista" das teorias ou dos conhecimentos específicos da Geografia, por parte dos docentes, poderia refletir na pouca atenção à construção da autonomia intelectual de seus licenciandos. Naquela ocasião, ela atentou para esse "isolamento" porque acredita no não atendimento às demandas das pesquisas e de posicionamentos que favoreçam um projeto político-pedagógicos que rompa com os limites dos processos formativos cujo desenvolvimento curricular seja o " $3+1$ ". A formação mencionada contribui com o conhecimento fragmentado e especializado que em muito dificulta a ação docente em sala de aula provocando um grande sentimento de "insegurança" e "medo" por parte dos licenciandos no momento de elaborar e/ou desenvolver as suas aulas. Vale mencionar que essa constatação não é nova, como fundamenta a professora Maria do Socorro Diniz, em referência à formação inicial de professores de Geografia:

[...] Isto se deve a um modelo hierárquico que, ao priorizar a pesquisa, forma mais especialistas. [...] a universidade dá muita importância ao conhecimento veiculado às pesquisas produzidas pelos professores/pesquisadores e pouca atenção à formação de professor. Dessa forma, essa instituição assume uma postura desigual na formação profissional, o que contribui para o seu desprestígio dentro e fora dela, ao relegar o ensino a um plano inferior [...] (2001, p. 63).

Tal estrutura curricular, vinculada ao Decreto Lei 1.190, de 4 de outubro de 1939 e à Reforma Universitária de 1968, correspondiam a uma licenciatura com duração de um ano de curso incluindo os estágios supervisionados. Nesses últimos, os estagiários deveriam buscar seu aprimoramento "técnico" no que resultaria num estágio formalista, de preenchimento de formulários e relatórios, que somado à "tecnoburocracia" escolar, gerou uma cultura de assinaturas de papéis e aulas artificiais (GONÇALVES, 2014). As práticas de estágios se constituíram, portanto, em instrumentos de integração e em treinamento prático, que precisava ensinar ao professor valores político-pedagógicos tecnicistas e utilitários; orientações estas que se fortaleceram com o Decreto $n^{\circ}$ 87.497/1982, Portaria Ministerial 399/89 (CAMPOS e SPAZZIANI, 2012 apud GONÇALVES, 2014).

Podemos justificar, dessa forma, a citação da professora Maria Socorro Diniz (1999) quando se refere à formação docente nos cursos de licenciatura de Geografia. Em sua pesquisa, os professores, ao narrarem as suas dificuldades como profissionais iniciantes, explicitam o 
distanciamento entre os conteúdos aprendidos na universidade e os que desenvolvem nas salas de aula escolares. Em outras palavras, a Geografia que se prende não é a Geografia que se ensina. Ela sustenta que isso se deve a um modelo hierárquico que, ao priorizar uma formação baseada na ideia de que um bom geógrafo será um bom professor, formaremos muitos mais especialistas em Geografia Urbana, Geografia Agrária, Geografia Física, Geografia Regional do que professores. Essa concepção é restritiva por ser fragmentada e privar o(a) licenciando(a) das questões e conteúdos pertinentes ao Ensino de Geografia (DINIZ, 1999; 2001). O documento já citado alhures evidencia:

[...] a concepção dominante [...] segmenta o curso em dois pólos [sic] isolados entre si: um caracteriza o trabalho na sala de aula e o outro, caracteriza as atividades de estágio. O primeiro pólo [sic] supervaloriza os conhecimentos teóricos, acadêmicos, desprezando as práticas como importante fonte de conteúdos da formação [...] O segundo pólo [sic] supervaloriza o fazer pedagógico, desprezando a dimensão teórica dos conhecimentos como instrumento de seleção e análise contextual das práticas. Neste caso, há uma visão ativista da prática [...] (Diretrizes Curriculares Nacionais para a Formação de Professores da Educação Básica, 2002, p. 21-22).

Recentemente, em relação às justificativas explicitadas pelas Diretrizes, concordamos com a professora Flaviana Gasparotti Nunes (2007) quando argumenta que

[...] o problema apontado, de fato, procede. Sabe-se que a estrutura até então vigente possibilitava este tipo de direcionamento, entretanto, não podemos afirmar [...] se realmente isso poderá ser resolvido conforme proposto pelas Diretrizes em termos de remodelação dos estágios e práticas (p. 62).

Se por um lado existe maior clareza e reconhecimento de que a formação inicial docente é diferente de outras habilitações, por outro, não há garantia de que reflexões sobre a prática docente, experiência, reflexões teóricas sobre o campo do conhecimento conhecido no Brasil como Ensino de Geografia sejam desenvolvidos nos respectivos cursos de licenciatura. Além disso, é preciso ainda relacionar a formação de professores não só a uma das "frentes" de trabalho da universidade (ensino), mas também às pesquisas e à extensão promovidas por esses cursos que se propõem à formação de professores. Nesse sentido, com a leitura e a interpretação dos relatórios produzidos pelos bolsistas de iniciação à docência envolvidos neste trabalho, pudemos perceber a concordância dessas análises a partir de outros processos formativos e a que eles estão submetidos. Suas descrições e reflexões estão chamando a atenção para as diversas clivagens entre os componentes curriculares da habilitação oferecida pelo Curso de 
Geografia, ainda que todos ressaltem o ensino e as aprendizagens de conteúdos específicos empenhados pelo competente corpo docente.

A princípio, parece-nos que as clivagens estão situadas nas (1) concepções de formação para a docência por parte dos docentes, sejam eles universitários (do mesmo ou entre departamentos envolvidos na habilitação Licenciatura) assim como pelos docentes das instituições escolares; e (2) a institucionalização de relações mais amplas entre esses espaços formativos que vão além dos convênios para a realização dos estágios supervisionados, tais como projetos de iniciação à docência e de reconhecimento (e valorização) dos professores regentes como protagonistas dos processos formativos por parte da universidade ${ }^{\text {iv }}$.

O Pibid veio a contemplar em grande medida essas clivagens. Todavia, antes de apresentarmos alguns dos resultados, vale compartilharmos alguns pressupostos políticos e filosóficos durante o nosso percurso. Com a identificação entre os projetos políticopedagógicos do curso de graduação e o do colégio estadual, a nossa equipe de trabalho se vê engajada na construção de um conhecimento geográfico escolar da emancipação não pelo viés de uma luta política sectária, solitária e individualista, mas retomando as perspectivas castoriadianas de uma emancipação autônoma através do conhecimento e da organização do grupo, a propósito, visto como um ato político. Com o domínio pelos alunos, dos saberes coletivos e individuais; por cada um e para todos (CASTORIADIS, 1982).

Esmeramo-nos em construir uma proposta sócio-educativa na qual os licenciandos devem resgatar o discurso de combate às desigualdades no processo pedagógico, estruturando a construção de conhecimentos escolares na valorização das diferenças no processo ensinoaprendizagem. Não pretendemos "denunciar" uma desigualdade vivenciada no cotidiano dos alunos da escola em tela, mas o nosso discurso pedagógico deve criar mecanismos didáticos que reforcem a ideia de que as diferenças são a realidade da humanidade, e que a partir delas podem ser buscados os tão sonhados caminhos que levam à justiça social (ARAÚJO et al., 2004; RAWLS, 1971). Sendo assim, esse grupo de trabalho crê que nem toda diferença é desigual, mas toda desigualdade deve ser eliminada pela valorização das diferenças.

O aluno, ao estudar uma Geografia das diferenças, mais do que um observador das desigualdades, será um agente de mudança ao respeitar as diferenças, e estas devem ser entendidas através dos conteúdos específicos da ciência do espaço. Se a Geografia é a ciência que estuda as interações homem/meio/sociedade, em escalas diversas, e o espaço pode ser lido pelas suas materialidades, símbolos e subjetividades, então, esta é a ciência que pode ensinar 
ao aluno a "ver através do olhar". Ao conseguir "ver", o alunado poderá atuar com propostas concretas para a modificação da realidade sem perder a sua "diferença” (ARAÚJO et al., 2004).

Concretizando o discurso da filosofia e das concepções pedagógicas em torno do ensino dessa disciplina escolar, pensamos em quatro pressupostos básicos (ALVAREZ et al., 2004): $a$ comunicação horizontal e vertical da Geografia; acreditamos num projeto docente de autonomização do corpo discente via o conhecimento dos conteúdos, conceitos e processos espaciais desenvolvidos, articuladamente, em todas as seriações do ensino básico, e na intensa integração de objetivos, metodologias e projetos educativos com as demais ciências escolares. O conhecimento não como um fim, mas como o intermediador do diálogo entre os que ensinam e os que aprendem. A construção de estratégias e metodologias que impulsionem os alunos a entenderem, questionarem e construírem os seus direitos e deveres, numa relação instituído/instituinte que transforme a coletividade próxima e distante. $O$ ato de educar como um ato de e para a cidadania, entendida como ação, individual e/ou coletiva, que busca o fim das desigualdades e a valorização das diferenças. Para ser atingida, a vida plural e equânime, local e global, deve ser conhecida, desejada e protegida.

\section{Reflexões sobre as experiências com as técnicas de ensino no Ensino Médio no âmbito do Pibid}

Ressaltamos aqui um dos objetivos do Pibid, o qual prevê a inserção dos licenciandos no cotidiano das escolas da rede pública de educação proporcionando-lhes oportunidades de criação e participação em experiências metodológicas e práticas docentes de caráter inovador e interdisciplinar. Tal iniciativa deve buscar a superação de problemas identificados no processo de ensino-aprendizagem. Como nos diz a Portaria 096/2013 que regulamenta o Programa,

“O Pibid é um programa da Coordenação de Aperfeiçoamento de Pessoal de Nível Superior (Capes) que tem por finalidade fomentar a iniciação à docência, contribuindo para o aperfeiçoamento da formação de docentes em nível superior e para a melhoria da qualidade da educação básica pública brasileira" (BRASIL, 2013, p. 1).

Dentre as atividades desenvolvidas na unidade escolar, estão leituras, reflexões e o desenvolvimento de atividades com o uso de diferentes metodologias no processo de ensinoaprendizagem: as chamadas técnicas de ensino. Para isso, tomamos como referências 
principais: Araújo (2008), Veiga (2008), Castellar \& Vilhena (2010), Kaercher (2007) e Rosa (2006). Segundo Castellar \& Vilhena (2010), a dinâmica da escola e o ritmo da sala de aula são diretamente influenciados pelo grande volume de informações trazidas pela mídia e as suas produções em nosso cotidiano. Isso influencia a nossa percepção, e, é claro, dos nossos alunos, de tempo e espaço, os dados do nosso conhecimento e a nossa visão de mundo. Tais situações devem ser consideradas no momento da seleção dos recursos que serão utilizados no ensino dos conteúdos didáticos. Podem ser de tipos variados e escolhidos a partir da intenção do professor e do(s) objetivo(s) proposto(s).

Aliamos essas colocações ao uso das chamadas técnicas de ensino, tomando por base o texto de Araújo (2008). As atividades desenvolvidas foram trabalhadas em salas de aula nos horários regulares, e, também, em oficinas em horário contraturno. Os planejamentos ocorreram (e ainda ocorrem) em horário específico semanalmente na escola ou no laboratório ${ }^{\mathrm{v}}$ ao qual está vinculado o nosso Subprojeto. Nestes momentos, colocamos as ideias que são avaliadas e discutidas considerando a viabilidade, organização, embasamento teórico e os conteúdos previstos no plano de curso para o ano escolar em questão.

Consideramos esses momentos fundamentais para a inserção efetiva dos licenciandos no ambiente escolar e nas práticas docentes, algo que, geralmente, não acontece nos tradicionais modelos estabelecidos para os estágios supervisionados das disciplinas de prática de ensino. Consideramos igualmente importante esta (tentativa de) formação inicial docente que procura aliar teoria e prática em sua construção, atenta às demandas da escola e aos conteúdos da disciplina escolar, e também aos fundamentos teóricos dos conhecimentos específicos da Geografia e da Educação. Mas, para isso, é preciso que ambos saberes - acadêmicos e escolares -, sejam tomados como base e objeto de pesquisa. Precisam ser considerados igualmente importantes, eliminando assim os (possíveis) distanciamentos entre a universidade e a escola básica. Esta reflexão também está presente em Rosa (2006), em seu texto Formação de Professores: Concepções e Práticas. Segundo a autora, "a formação inicial docente não pode continuar produzindo dicotomias entre teoria e prática, pesquisa e ensino, conteúdo específico e pedagógico” (Op. cit., p. 22).

Dentre as atividades produzidas pelo grupo, relataremos aqui: Produção de Textos I e II e Colagem com Música. A primeira foi desenvolvida no espaço da Oficina: uma sequência de atividades compreendidas em dez encontros, em horário contraturno, realizadas em diferentes espaços da escola: auditório, biblioteca, sala de informática e também numa área de 
lazer próxima. A segunda deu-se em horário regular, em sala de aula, e fez parte das avaliações do bimestre.

Produção de Textos foi a terceira dentre as atividades desenvolvidas nas oficinas e foi dividida em dois dias ("I" e "II"). Consistiu em uma atividade interdisciplinar com a disciplina Língua Portuguesa, e o seu objetivo geral era melhorar a produção textual dos alunos, e, também, prepará-los para a redação do ENEM e outros processos seletivos. No primeiro dia, retiramos os alunos da escola e nos reunimos numa área de lazer próxima: o Campo de São Bento. Neste dia, nos dividimos em quatro subgrupos (cada um deles coordenado por um licenciando) e realizamos leituras e discussões de textos, cujos temas relacionavam-se à Geografia Urbana ${ }^{\text {vi }}$, assunto abordado nas aulas daquele bimestre letivo. Em seguida, foi proposto um jogo de mímicas envolvendo conceitos principais do tema em questão. Como tarefa para o próximo encontro, os alunos deveriam produzir textos dissertativos relacionados ao assunto discutido em seu respectivo subgrupo.

No segundo dia, lemos e discutimos os textos produzidos pelos próprios alunos analisando os seus argumentos. Foi exibido o documentário Hiato, de Vladimir Seixas, sobre o "Movimento Rolezinho", quando um grupo de manifestantes do Movimento dos Trabalhadores Sem Teto (MTST) realizou um passeio ou "ocupação" em um shopping da Zona Sul carioca em 2000. Em seguida, houve um debate acerca das reações de alguns dos lojistas, seguranças, funcionários desse espaço de consumo orientado pelos licenciandos. Contamos com a colaboração de uma professora de Língua Portuguesa, que ministrou uma aula sobre a estrutura do texto dissertativo-argumentativo e da resenha (crítica e descritiva). Novamente, foram propostas produções textuais aos alunos, desta vez, sobre o vídeo e o debate. Para as correções, também contamos com a parceria da professora colaboradora.

A atividade Colagem com Música foi planejada a partir de uma adaptação da ideia proposta por Kaercher (2007) no texto intitulado "Práticas geográficas para lerpensar o mundo, converentendersar com o outro e entenderscobrir a si mesmo". Neste capítulo, o autor nos apresenta esta e outras atividades práticas diferenciadas que podem ser desenvolvidas no ensino de Geografia. Esta atividade aconteceu no quarto bimestre, e teve por objetivo geral instigar novas discussões e olhares nas aulas de Geografia da População a partir do uso de outra linguagem em sala de aula: a música como um recurso didático.

Elencamos os seguintes objetivos específicos: estabelecer relações entre os assuntos estudados pela Geografia da População e as manifestações culturais e artísticas do nosso país; 
provocar reflexão e leitura crítica das representações da população brasileira que são criadas a partir das músicas nacionais; e, conhecer melhor os alunos e, por meio das imagens escolhidas por eles e das apresentações (em forma de seminário), percebermos as suas leituras de mundo.

Em grupos, a partir de uma música de livre escolha, os alunos deveriam fazer uma montagem, colagem ou desenho que tivesse relação com a letra. A música deveria compreender temas relativos à população brasileira (contexto nacional ou regional), não importando o ritmo e a autoria. No dia marcado, os alunos deveriam: apresentar seus trabalhos, justificando a escolha da música e explicando as imagens selecionadas; trazer a música em pen drive ou no celular para ser ouvida pela turma; e, se possível, utilizar um espaço fora da sala de aula ou organizá-la de modo circular.

A avaliação da atividade pelos licenciandos e professora envolveu: a coerência da música escolhida com o tema geral (população brasileira); adequação e coerência das imagens ao contexto da música, a partir da justificativa e explicação dada por cada grupo; correta apresentação à turma e capricho com o trabalho. Ao final, os melhores cartazes foram expostos no hall de entrada da escola e apresentados na maratona cultural escolar.

Percebemos nos alunos, ao longo do ano, um progressivo interesse pelas aulas de Geografia, resultando em maior assiduidade e pontualidade, melhoria das notas e menor percentual de alunos reprovados ao final do ano letivo (2014). Porém, interessam-nos não apenas os números, mas os resultados em relação à construção de conhecimentos de forma ampla e às relações entre os sujeitos que integram o ambiente escolar. Nos momentos compartilhados em salas de aula e nas oficinas, procuramos estabelecer uma comunicação horizontal, respeitando os alunos como sujeitos portadores de um conjunto de saberes individuais e coletivos. As atividades foram bem aceitas pelas turmas, com exceção de alguns poucos alunos. Neste trabalho, relatamos apenas duas experiências, porém, ao longo do ano (2014), várias foram desenvolvidas, resultando num número crescente de alunos inscritos nas oficinas.

De acordo com as falas dos próprios alunos, foram marcantes na primeira atividade: a saída do ambiente escolar, aprender conceitos a partir de um jogo simples - a mímica -, e ver com outro olhar o "Movimento Rolezinho" a partir do documentário e debate. Foi relatado a “interessante ideia" de unir as disciplinas Língua Portuguesa e Geografia numa mesma atividade. 
A segunda atividade trouxe-nos resultados igualmente gratificantes: as músicas, em ritmos variados, com preponderância do rap e hip hop, apresentavam letras que discutiam problemas sociais, econômicos e políticos do nosso país. Houve engajamento na confecção dos cartazes, que ficaram muito criativos; praticamente todos foram expostos. A maior parte dos alunos fez bom uso da autonomia, na medida em que não listamos nem direcionamos ritmo ou estilo musical. Fomos surpreendidos positivamente pelas suas escolhas e justificativas coerentes com o conteúdo trabalhado.

Consideramos parciais os resultados na formação dos licenciandos (as bolsas têm vigência de vinte e quatro meses). Contudo, percebemos maior familiaridade deles com o ambiente escolar, incluindo o corpo docente e administrativo da escola. Observamos um crescimento contínuo em relação à construção das suas práticas docentes: elaboração de planos de aula e ministração das mesmas, preparação de atividades e avaliações e acompanhamento do processo global das aprendizagens dos alunos, com criação de estratégias para a superação dos desafios; e de modo sempre reflexivo, incluindo a autoavaliação.

\section{Considerações finais}

Consideramos pertinentes e norteadoras as reflexões acerca das técnicas de ensino e do uso de diferentes linguagens no ensino da Geografia. Diante dos desafios cotidianos no processo de ensino-aprendizagem, faz-se necessário criar estratégias e diferentes metodologias para obter resultados amplos, que ultrapassem as avaliações, notas e aprovações escolares, e visem atender os educandos de modo que possam questionar e construir os seus direitos e deveres. Compreendemos o ato de educar como a construção de estratégias e metodologias que impulsionem os alunos a entenderem a sua formação como um ato de e para a cidadania. Compartilhamos também as reflexões de Rosa (2006), Gonçalves (2014) e Barbosa (2014), quando questionam o ainda existente distanciamento entre a teoria e a prática na formação inicial docente, assim como quando propõem estratégias para superação deste desafio na educação brasileira. Entendemos que o Pibid, enquanto uma política pública voltada à educação, tem possibilidades de ser um importante (não único) espaço para discussão e superação de muitos dos desafios que permanecem na formação de licenciandos e na educação básica. 
Vale também mencionar a reflexão relativa aos conceitos até então adotados. O significado da didática ao vincular-se à produção do conhecimento escolar é parte dessa reflexão. Com a técnica das oficinas empregada, depreendemo-nos que a unidade entre a teoria e a prática é assegurada pela simultaneidade e a reciprocidade, pela autonomia e dependência de uma em relação à outra (VEIGA, 2008). Compreendemos que essa relação se dá como processo por meio do qual se constrói o conhecimento. No entanto, em reuniões de análise e avaliação do que foi desenvolvido, os bolsistas salientam as "perdas" ou "variações" ocorridas entre os conteúdos que se aprende durante o curso de graduação em Geografia e no ato da didática.

Em nosso "retorno" ao campo teórico, encontramos Alice Ribeiro Casemiro Lopes que define tal termo no campo da mediação de caráter dialético. A autora defende que haveria maior favorecimento ao processo de transformação do conhecimento acadêmico em escolar por um “[...] processo de constituição de uma realidade a partir de mediações contraditórias, de relações complexas, não imediatas [...]" (1997, p. 209). Reconhecemos que no processo de transformação do conhecimento produzido em determinado contexto institucional universitário - há deturpações em seu deslocamento para outros contextos de aprendizagem. Isso foi verificado. Logo, vale refletir a representação que os nossos bolsistas fazem desse “deslocamento": por que "perdas"? Por que "subtração" e como a realiza? Até que ponto essas restrições do conhecimento escolar "subtraído" obstaculizaria a formação plena dos nossos estudantes do Ensino Médio no sentido de prática política?

A partir das colocações acima, consideramos este trabalho ainda em andamento, buscando a superação do distanciamento dos campos teórico e prático no processo de ensinoaprendizagem dos conhecimentos geográficos no espaço escolar e na formação docente.

\section{Referências}

ALVAREZ, C.; BARBOSA, P. H.; FORTUNA, D. S., SILVA, A. C. P. O Ensino de Geografia e sua prática no Fundamental e Médio das escolas da rede oficial. (s/d) Rio de Janeiro: PUC-Rio, 2004.

ARAÚJO, E. A.; BARCELOS, I.; FORTUNA, D. S.; SILVA, A. C. P. Reforma Curricular de Geografia no Ensino Médio: estratégias para a autonomização discente através de uma linguagem curricular interdisciplinar do saber geográfico. Rio de Janeiro: Colégio de 
Aplicação da Pontifícia Universidade Católica do Rio de Janeiro. Rio de Janeiro/Instituição Teresiana, 2004.

ARAÚJO, J. C. S. Para uma análise das representações sobre as técnicas de ensino. In: VEIGA, I. P. A. (org.). Técnicas de ensino: por que não? $19^{\circ}$ edição. Campinas: Papirus, 2008 [1991].

BARBOSA, M. V. O Pibid e as culturas formativas no âmbito dos cursos de licenciatura. In: BARBOSA, M. V.; DANTAS, F.B.A. (orgs.). Reflexões sobre a formação inicial de professores no Pibid. Campinas: Mercado de Letras, 2014.

BRASIL. Conselho Nacional de Educação. Dá nova redação ao Parecer CNE/CP 21/2001, que estabelece a duração e a carga horária dos cursos de Formação de Professores da Educação Básica, em nível superior, curso de licenciatura, de graduação plena. Parecer $\mathrm{CNE} / \mathrm{CP} \mathrm{n}^{\circ}$ 28, de 2 de outubro de 2001. Brasília, Diário Oficial [da] República Federativa do Brasil, 18 jan 2002, Seção 1, p. 31.

.Programa Institucional de Bolsa de Iniciação à Docência - PIBID. Brasília: Coordenação de Aperfeiçoamento de Pessoal de Nível Superior (CAPES). Disponível em www.capes.gov.br/educacao-basica/capespibid. Acesso em 06/06/2015.

CASTELLAR, S.; VILHENA, J. Ensino de geografia. São Paulo: Cengage Learning Edições, 2010.

CASTORIADIS, C. A instituição imaginária da sociedade. São Paulo: Paz e Terra, 1982. DINIZ, M. S. A Geografia que a gente aprende não é a Geografia que a gente ensina. Revista do Departamento de Geografia UFRJ, v. 1, nº 7, 2001.

GONÇALVES, A. R. Matrizes formativas históricas e marcas recentes na formação inicial de professores no Brasil. In: BARBOSA, M. V.; DANTAS, F.B.A. (orgs.). Reflexões sobre a formação inicial de professores no Pibid. Campinas: Mercado de Letras, 2014.

KATUTA, A. M. Universidade em ruínas? Geografia: Revista do Departamento de Geociências, vol. 11, nº 1, Londrina: Editora da UEL, 2002, p. 131-138.

. A reforma universitária no contexto dos projetos políticos pedagógicos dos cursos de graduação In: LIMA, M. G.; LOPES, C. L. Geografia e Ensino: conhecimento científico e sociedade. Maringá: Massoni, 2007.

LOPES, A. C. R. Conhecimento escolar em química: processo de mediação didática da ciência. Química Nova, v. 20, nº 5, 1997, p. 563-568.

MATURANA, H. Ontologia da realidade. Belo Horizonte: UFMG, 2001.

NUNES, F. G. Os projetos pedagógicos de geografia e a reforma universitária In: LIMA, M. G.; LOPES, C. L. Geografia e Ensino: conhecimento científico e sociedade. Maringá: Massoni, 2007. 
RAWLS, J. Uma teoria da justiça. São Paulo: Ed. Martins Fontes, 1971.

KAERCHER, N. A. Práticas geográficas para lerpensar o mundo, converentendersar com o outro e entenderscobrir a si mesmo. In: REGO, N. et. al. (org.) Geografia: práticas pedagógicas para o ensino médio. Porto Alegre: Artmed, 2007.

ROSA, D. E. G. Formação de professores: concepções e práticas. In: CAVALCANTI, L. de S. (org.) Formação de professores: concepções e práticas em Geografia. Goiânia: Ed. Vieira, 2006.

VEIGA, I. P. A. Nos laboratórios e oficinas escolares: a demonstração didática. In: (org.). Técnicas de ensino: por que não? 19º edição. Campinas, Papirus, 2008 [1991].

\footnotetext{
${ }^{\mathrm{i}} \mathrm{O}$ teor desse trabalho foi apresentado no $4^{\circ}$ Congresso Pesquisa do Ensino - As Ciências Humanas na Educação, promovido pelo Sindicato dos Professores de São Paulo (Sinpro-SP) e realizado entre os dias 20 e 22 de agosto de 2015. Outrossim, este foi publicado em $c$ d-rom do próprio evento sob o registro 978-85-67230-3 (ISBN). Para esta publicação, além de nossa revisão, houve alterações e aprofundamento de algumas reflexões de acordo com as discussões realizadas em nossas reuniões de estudo e planejamento de atividades pedagógicas, aliás, feitas semanalmente.

ii Professor Adjunto da Faculdade de Educação da Universidade Federal Fluminense, Coordenador do Subprojeto de Geografia (Niterói) do Programa Institucional de Bolsas de Iniciação à Docência (Pibid).

iii Professora vinculada à Secretaria Estadual de Educação do Rio de Janeiro (SEEDUC-RJ), Colégio Estadual Manuel de Abreu e mestranda do Programa de Pós Graduação em Educação da Pontifícia Universidade Católica do Rio de Janeiro - PUC-Rio Professora de Geografia/Profa, Supervisora do Subprojeto de Geografia (Niterói) do Programa Institucional de Bolsas de Iniciação à Docência (Pibid).

iv Para uma afirmação contundente será necessário maior tempo e aprofundamento para a nossa investigação. Esclarecemos que os professores que compõem o Núcleo Docente Estruturante (NDE) do Curso de Geografia em tela reunem-se, com frequência desde o ano de 2015, para discutir a reformulação curricular das habilitações oferecidas. Até o momento do envio deste texto, não houve a apresentação do resultado desses trabalhos.

v Laboratório de Ensino de Geografia (LEGEO), situado na Faculdade de Educação (FE) da Universidade Federal Fluminense (UFF).

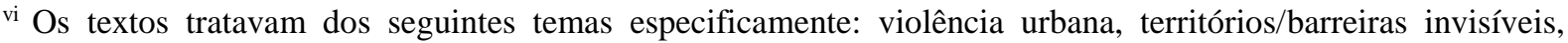
mobilidade urbana e favelização.
} 